\title{
A implantação da EaD: Um estudo sobre os dispositivos legais e a expansão do curso de Pedagogia
}

\author{
Distance education: A study on the legal devices and expansion of the Pedagogy course
}

Flavia Aparecida Machado Fortes ${ }^{1}$

Adair Mendes Nacarato ${ }^{2}$

\section{Resumo}

Este estudo centra-se na análise da implantação e do crescimento da Educação a Distância no Brasil. Para isso, realizou-se um levantamento a partir de documentos oficiais divulgados pelo Ministério da Educação (MEC) e pela Associação Brasileira de Educação a Distância (Abed), criando, assim, um histórico cronológico de acontecimentos e dados que envolvem o ensino superior na modalidade de educação a distância. O objetivo deste artigo $^{3}$ é conhecer o percurso legal que embasa a implantação de cursos superiores EaD no Brasil e analisar o crescimento das matrículas em cursos de Pedagogia EaD. Utilizou-se como metodologia a análise documental, em documentos disponíveis no Portal MEC, datados do período de 1996 a 2017. Constatou-se que a busca por cursos de graduação a distância vem aumentando ano a ano, destacando-se a procura por cursos de licenciatura, sendo que o curso de Pedagogia liderou as matrículas realizadas nos anos de 2016 e 2017. A análise possibilitou concluir que, com a expansão e a flexibilização da abertura de cursos $\mathrm{EaD}$, bem como os valores das mensalidades destes cursos, possibilitou o acesso de uma maior parcela da população aos cursos de graduação, porém, é preciso olhar para além do número de ingressantes em busca de qualidade na formação.

Palavras-chave: Graduação; Educação a Distância; Legislação da educação.

\begin{abstract}
This study focuses on the analysis of the implementation and growth of Distance Education in Brazil. For this, a survey was carried out based on official documents released by the Ministry of Education (MEC) and the Brazilian Association for Distance Education (ABED), thus creating a chronological history of events and data involving higher education in distance education modality. The objective of this article is to understand the legislation the implementation of higher education courses in Brazil and to analyze the growth of enrollments in Pedagogy learning educacion. Documentary analysis was used as methodology in documents available on the MEC Portal, dated from 1996 to 2017. It was found that the search for distance undergraduate courses has been increasing year by year, highlighting the demand for graduate courses, and the Pedagogy course led the enrollments made in the years 2016 and 2017. The analysis made it possible to conclude that the expansion and flexibility of

\footnotetext{
${ }^{2}$ Doutora, Universidade São Francisco, Itatiba, SP, Brasil. ada.nacarato@ gmail.com

${ }^{3}$ Este artigo compõe uma pesquisa de doutorado, no modelo multipaper, realizada com o apoio financeiro da Coordenação de Aperfeiçoamento de Pessoal de Nível Superior - Brasil (CAPES).
}

${ }^{1}$ Mestre, Universidade São Francisco, Itatiba, SP, Brasil. flavia.machadofortes@ gmail.com
\end{abstract}


distance education, and low monthly fees made it possible for the population access to higher education courses, however, it is necessary to study the quality of academic education.

Keywords: Higher Education; Distance Education; Educational legislation.

\section{Introdução}

A educação a distância não é algo novo no Brasil. Desde o início do século XIX já existiam no País os primeiros cursos que utilizavam correspondências ou rádio como recurso didático. Na década de 1940, ganharam espaço os cursos profissionalizantes, sendo as instituições de referência desse período o Instituto Monitor e o Instituto Universal Brasileiro. Assim, a educação a distância $(\mathrm{EaD})$ não envolve só a modalidade que vemos na atualidade, em que se utiliza a internet como recurso educacional, mas uma outra modalidade de ensino que vem se reinventando e que, hoje, adota a tecnologia da informação e comunicação como estratégia para expansão e oferta de cursos.

A graduação a distância se tornou possível em 1996, quando o Ministério da Educação (MEC) começou a discutir a realização de cursos de ensino superior nessa nova modalidade. A oferta do primeiro curso, ainda em caráter experimental, aconteceu na Universidade Federal do Mato Grosso, com curso de formação de professores. A proposta inicial da EaD era atender às necessidades de estudantes que residiam longe dos grandes centros ou das universidades e que de outra forma não conseguiriam acesso à educação superior.

Mais de 20 anos se passaram desde o primeiro dispositivo legal sobre a EaD. Este artigo tem como objetivo, conhecer o percurso legal que embasa a implantação de cursos superiores na modalidade de Educação a Distância e analisar o crescimento das matrículas em cursos de Pedagogia EaD. Como metodologia utilizamos a análise documental, em documentos legais disponíveis no Portal MEC, publicados no período de 1996 e 2017. Nessa análise teceremos algumas reflexões quanto à forma como essa modalidade de graduação vem se ampliando e as implicações para a formação de professores para atuar no início da escolarização das crianças. Trata-se de um estudo de natureza bibliográfico-exploratória, em busca de leis, portarias e outros documentos que abordem a Educação a Distância - em particular, o curso de Pedagogia. Utilizamos também informações fornecidas pela Associação 
Brasileira de Educação a Distância (ABED) e divulgadas nos Censos da EaD nos anos de 2014 a 2018.

Para a pesquisa foram localizados 15 documentos (Leis, Portarias, Relatórios e Decretos) do período de 1996 a 2017, que abordam especificamente os cursos superiores na modalidade EaD. Com eles, construímos os caminhos percorridos pela educação superior a distância no Brasil como forma de olhar desde os primeiros passos para a implantação dessa modalidade de ensino até a atualidade. Entendemos que conhecer esse percurso se faz necessário para quem pretende discutir a $\mathrm{EaD}$ e seus impactos.

Inicialmente daremos um enfoque ao contexto nacional para, em seguida, apresentarmos dados do curso de Pedagogia e, finalmente, direcionamos nosso olhar para as instituições privadas, considerando que a maioria dos cursos está nelas locados, além de ser o foco de nossa investigação.

\section{A educação a distância e os dispositivos legais}

A primeira vez em que a educação a distância foi abordada pelo MEC foi na Lei de Diretrizes e Bases da Educação (LDB), Lei n. ${ }^{\circ}$ 9.394/96, que apontou para a implantação dessa modalidade de ensino em todos os níveis do sistema educacional e definiu como papel da União a regulamentação destes cursos (Brasil, 1996). A educação a distância é discutida na LDB em seu artigo 80, que atribui ao poder público o incentivo a programas de ensino a distância, a responsabilidade pelo controle, pela avaliação, e a competência para autorizar a realização de cursos nessa modalidade de ensino.

No ano de 1998, foram publicados dois importantes documentos: o Decreto n. ${ }^{\circ} 2.494$, que regulamentou o artigo 80 da LDB e dispôs sobre a autorização e a oferta de cursos na modalidade a distância; e o Decreto n. ${ }^{\circ}$ 2.561, que alterou os artigos, 11 e 12 , do Decreto n. ${ }^{\circ}$ 2.494, delegando ao MEC a competência para o credenciamento de Instituição de Ensino Superior (IES) para oferta de cursos na modalidade EaD.

Em 1998, havia no País apenas um curso de Graduação a Distância, oferecido pela Universidade Federal do Mato Grosso em caráter experimental e voltado para a formação de professores do ensino fundamental da rede pública. A partir dessa experiência, outras IES 
começaram a realizar pedidos de novos cursos na modalidade $\mathrm{EaD}$, a maioria deles de graduação em formação de professores.

Os atuais professores do ensino fundamental são o público alvo principal destes cursos, na medida em que sejam afetados pelo art. $87, \S 4^{\circ}$, da LDB, o qual estabelece que, até o final da década da Educação, ou seja, 2006, somente serão admitidos "professores habilitados em nível superior ou formados por treinamento em serviço". Estima-se que essa exigência legal tenha motivado uma demanda pontual da ordem de 700 mil novas vagas. (BRASIL, 2002, p.8)

Em 2002, foi publicada a Portaria MEC n. ${ }^{\circ}$ 335, de 6 de fevereiro de 2002, que cria a Comissão Assessora para Educação Superior a Distância, tendo como objetivo elaborar uma proposta de normas que regulamentassem a oferta de cursos EaD. Essa comissão foi responsável por organizar um relatório, e participaram da elaboração deste documento professores e representantes do MEC. O documento traz uma análise do contexto da Educação a Distância, um roteiro com elementos considerados essenciais para um projeto de Curso Superior na modalidade EaD e uma proposta de Regulamentação para a Educação a Distância, com o objetivo de estabelecer normas para a implantação de cursos.

Este documento apresenta um cenário crescente do número de egressos do Ensino Médio e vislumbra na $\mathrm{EaD}$ um recurso para se alcançar a ampliação de vagas no ensino superior. Aponta ainda que a Portaria MEC n. 335 foi criada em um momento em que milhares de alunos já estavam matriculados em cursos de graduação a distância autorizados pelo MEC (BRASIL, 2002).

Em dezembro de 2004, foi publicada a Portaria n. ${ }^{\circ} 4.059$, que instituiu a modalidade de ensino semipresencial, considerando que as IES estariam autorizadas a implantar no currículo de seus cursos disciplinas na modalidade semipresencial, desde que esta oferta não ultrapassasse $20 \%$ da carga horária do curso. Essa portaria aborda ainda a realização de avaliações e a necessidade de as IES comunicarem ao MEC o Plano de Ensino das disciplinas realizadas neste novo formato.

No ano seguinte, em 2005, o Grupo de Trabalho em EaD no Ensino Superior, vinculado ao MEC, elaborou um documento apontando algumas preocupações levantadas nos debates do grupo, envolvendo questões técnicas, ideológicas, políticas e educacionais dos cursos a distância. Entre elas estão: a necessidade de uma lei que estabeleça diretrizes e princípios de qualidade na $\mathrm{EaD}$; a importância de estimular e viabilizar acesso à tecnologia de comunicação; e a falta de clareza sobre o significado da EaD. Este mesmo documento 
apontava a necessidade de avaliar a qualidade, além de orientar sobre a utilização de tecnologias de informação e comunicação (TIC) e a importância de que os cursos de graduação a distância fossem bem definidos no Plano de Desenvolvimento Institucional (PDI) e no Projeto Político-Pedagógico da IES (BRASIL, 2005).

Ainda no ano de 2005, o Decreto n. ${ }^{\circ}$ 5.622, de 19 de dezembro de 2005, trouxe em seu Artigo 1. ${ }^{\circ}$ a definição de educação a distância: "Modalidade educacional na qual a mediação didático-pedagógica nos processos de ensino e aprendizagem ocorre com a utilização de meios e tecnologias de informação e comunicação, com estudantes e professores desenvolvendo atividades educativas em lugares ou tempos diversos" (BRASIL, 2005, [s.p.]).

Este decreto trouxe orientações sobre o desenvolvimento dos cursos, matrículas e transferências, a avaliação de desempenho do estudante, certificados e instruções sobre o credenciamento de IES para oferta de cursos na modalidade a distância.

A Portaria n. ${ }^{\circ}$ 873, de 7 de abril de 2006, autorizou, em caráter experimental, a realização de cursos superiores a distância, ofertados por IES Federais. Com esta normativa, as universidades públicas puderam se credenciar para a oferta de cursos EaD.

Após esta portaria, em 2006, foi criada a Universidade Aberta do Brasil (UAB), a partir de uma articulação entre governo federal, estadual e municipal e IES públicas, tendo por finalidade expandir e interiorizar a oferta de cursos $\mathrm{EaD}$, e promover a expansão de vagas no Ensino Superior no País. A prioridade inicial da UAB era a oferta de cursos de licenciatura e de formação (inicial e continuada) de professores (BRASIL, 2006). Atualmente, existem no Brasil 555 polos da UAB, que atendem 170 mil alunos em cursos de licenciatura, bacharelado, tecnologias, além de cursos de especialização lato sensu.

Em 10 de janeiro de 2007, a Portaria n. ${ }^{\circ} 2$ do MEC estabeleceu os procedimentos de regulação e avaliação da educação superior a distância. Nesse documento, é regulamentado o credenciamento de IES para realização de cursos na modalidade a distância, e instituída a exigência de que as IES tenham Polos de Apoio Presencial.

Ainda em 2007, o MEC divulgou documento intitulado "Referenciais de Qualidade para Educação Superior a Distância”, considerando a importância desta modalidade de ensino para a expansão do ensino superior e ressaltando que, apesar de este documento não ser uma lei, seria o "norteador para subsidiar atos legais do poder público no que se refere aos processos específicos de regulação, supervisão e avaliação da modalidade citada" (BRASIL, 2007, p. 2). 
Os Referenciais de Qualidade para Educação Superior a Distância indicam que "um projeto de curso superior a distância precisa de forte compromisso institucional em termos de garantir o processo de formação que contemple a dimensão técnico-científica para o mundo do trabalho e a dimensão política para a formação do cidadão" (BRASIL, 2007, p. 7). Ainda, segundo o documento:

O uso inovador da tecnologia aplicado à educação, e mais especificamente, à educação a distância deve estar apoiado em uma filosofia de aprendizagem que proporcione aos estudantes a oportunidade de interagir, de desenvolver projetos compartilhados, de reconhecer e respeitar diferentes culturas e de construir o conhecimento. (BRASIL, 2007, p.9)

Este documento reforçou que a essência dos cursos superiores deve ser a educação, independentemente de ser na modalidade presencial ou a distância.

Um curso superior a distância precisa estar ancorado em um sistema de comunicação que permita ao estudante resolver, com rapidez, questões referentes ao material didático e seus conteúdos, bem como aspectos relativos à orientação de aprendizagem como um todo, articulando o estudante com docentes, tutores, colegas, coordenadores de curso e disciplinas e com os responsáveis pelo sistema de gerenciamento acadêmico e administrativo. (BRASIL, 2007, p. 11)

Destacou, ainda, a necessidade de trabalhos contextualizados e interdisciplinares, dada a importância da formação do indivíduo cidadão, além de apontar a necessidade de os cursos superiores a distância terem encontros presenciais, como atendimento às exigências legais. Apresentou também diretrizes para a elaboração de material didático (que deve incluir um guia geral do curso que apresente o sistema), a avaliação da aprendizagem, a avaliação institucional, a organização didático-pedagógica, do corpo técnico-administrativo e do corpo docente, a infraestrutura de apoio e do polo de apoio presencial (BRASIL, 2007).

Os pareceres CNE/CES n. 195 e n. ${ }^{\circ}$ 197, publicados em 2007, estabeleceram instrumentos de avaliação para credenciamento de IES para oferta de cursos $\mathrm{EaD}$, determinando que estes instrumentos são de responsabilidade do Instituto Nacional de Estudos e Pesquisas Educacionais Anísio Teixeira (INEP).

O Relatório de Gestão da Secretaria de Educação a Distância (SEED) do ano de 2008 aponta que, de 1999 a 2008, 33.993 professores foram formados em cursos na modalidade a distância, ofertados em parceria entre MEC, estados e municípios (BRASIL, 2008). 
No ano de 2015, foi publicado o Parecer n. ${ }^{\circ}$ 564, com as diretrizes para oferta de cursos superiores em $\mathrm{EaD}$, formulado com a participação de diversos interlocutores vinculados à comunidade acadêmica, como associações, faculdades e universidades públicas e privadas, representantes de professores e de estudantes.

A Resolução n. ${ }^{\circ}$ 1, de 11 de março de 2016, determinou normas nacionais para a oferta de Cursos Superiores na Modalidade EaD, atualizando e organizando, em um único documento, informações tratadas anteriormente em outras portarias.

Em maio de 2017, a legislação que regulamenta a EaD no País foi atualizada pela Portaria n. ${ }^{\circ} 11$, e apontou como principal mudança a possibilidade de as IES criarem polos de EaD sem a necessidade de autorização do MEC, condicionando o número de abertura anual de polos ao Índice Geral de Cursos Avaliados da Instituição (IGC). Dessa forma, as IES com conceito institucional 3 poderão abrir anualmente até 50 polos de educação a distância, sem precisar pedir autorização ao MEC; as IES com conceito institucional 4 poderão abrir até 150 polos educacionais; e aquelas com conceito 5 poderão abrir anualmente 250 polos educacionais para realização de seus cursos da modalidade a distância.

Outra mudança importante, determinada pela Portaria $n^{\circ} 11$, é que uma IES não precisa possuir cursos presenciais para solicitar o credenciamento de cursos EaD. É também esta portaria que regulamenta a oferta de cursos a distância para o Ensino Médio e para a Educação técnica de nível médio (MEC, 2017).

Quadro 1: Legislação EaD no Brasil

\begin{tabular}{|c|c|c|}
\hline Ano & Documento & Resumo \\
\hline 1996 & Lei n. $^{\circ} 9.394$ & Lei de Diretrizes e Bases da Educação (LDB) \\
\hline \multirow[t]{2}{*}{1998} & Decreto n..$^{\circ} 2.494$ & Dispõe sobre a oferta de cursos EaD \\
\hline & Decreto n. $^{\circ} 2.561$ & Competência de credenciamento de IES para oferta de cursos EaD \\
\hline 2002 & Portaria n. 335 & Relatório da Comissão para Educação Superior a Distância \\
\hline 2004 & Portaria n. ${ }^{\circ} 4.059$ & Institui a modalidade semipresencial \\
\hline 2005 & Decreto n..$^{\circ} 5.622$ & $\begin{array}{l}\text { Regulamenta o art. } 80 \text { da Lei } \text { n. }^{\circ} \text { 9.394, de } 20 \text { de dezembro de } 1996 \text {, } \\
\text { que estabelece as diretrizes e bases da educação nacional }\end{array}$ \\
\hline \multirow[t]{2}{*}{2006} & Portaria n. ${ }^{\circ} 873$ & $\begin{array}{l}\text { Autoriza, em caráter experimental, a oferta de cursos superiores a } \\
\text { distância nas Instituições Federais de Ensino Superior. }\end{array}$ \\
\hline & Decreto n. $^{\circ} 5.800$ & Institui o Sistema Universidade Aberta do Brasil \\
\hline \multirow[t]{4}{*}{2007} & Portaria n. $^{\circ} 2$ & Regulação e avaliação da Educação Superior a Distância \\
\hline & $\begin{array}{l}\text { Referenciais de } \\
\text { Qualidade para Educação } \\
\text { a Distância }\end{array}$ & $\begin{array}{l}\text { Referencial norteador para subsidiar atos legais do poder público no } \\
\text { que se refere aos processos específicos de regulação, supervisão e } \\
\text { avaliação da modalidade EaD. }\end{array}$ \\
\hline & Parecer n. ${ }^{\circ} 195$ & $\begin{array}{l}\text { Diretrizes para a elaboração dos instrumentos de avaliação para } \\
\text { credenciamento de IES para a oferta de cursos superiores EaD }\end{array}$ \\
\hline & Parecer n. $^{\circ} 197$ & $\begin{array}{l}\text { Instrumentos de avaliação para credenciamento de IES para a oferta de } \\
\text { cursos superiores EaD }\end{array}$ \\
\hline
\end{tabular}




\begin{tabular}{|l|l|l|}
\hline 2015 & Parecer n. $^{\text {5 } 564}$ & $\begin{array}{l}\text { Diretrizes e Normas Nacionais para a oferta de Programas e Cursos de } \\
\text { Educação Superior EaD }\end{array}$ \\
\hline 2016 & Resolução n. $^{\text {o } 1}$ & $\begin{array}{l}\text { Diretrizes e Normas Nacionais para a Oferta de Programas e Cursos de } \\
\text { Educação Superior EaD }\end{array}$ \\
\hline 2017 & Portaria n. $^{\text {. } 11}$ & $\begin{array}{l}\text { Normas para credenciamento de instituições e oferta de cursos } \\
\text { superiores EaD }\end{array}$ \\
\hline
\end{tabular}

Fonte: adaptado pelas autoras a partir de documentos do Portal MEC

A Portaria Normativa $\mathrm{n}^{\mathrm{o}} 11$ de 2017, foi o último documento oficial publicado no Portal MEC, que tratou a educação superior a distância e sua regulamentação. Até aqui procuramos reconstruir uma linha cronológica dos dispositivos legais que organizam a oferta da educação a distância no País.

Anualmente, a ABED divulga um relatório com informações sobre cursos e IES que atuam na área de educação a distância. No ano de 2016, o número de alunos matriculados em curso EaD era de 135.236 alunos (ABED, 2017). O Censo 2018 indica que o número de matrículas em cursos regulamentados totalmente a distância foi de 1.320.025 alunos. Deste total, 215.450 matrículas foram realizadas em cursos de licenciatura (ABED, 2018). O crescimento do número de matrículas coincidiu com a flexibilização da abertura de novos polos de educação, regulamentados pela Portaria n. ${ }^{\circ} 11$, de 20 de junho de 2017.

Uma preocupação frequente das IES que atuam com cursos a distância é a alta taxa de evasão de seus alunos. Em 2016, essa taxa foi de $11 \%$ a 25\%, tendo sido considerada a falta de tempo para dedicação aos estudos como a maior causa da evasão, seguida da dificuldade de adaptação à modalidade. O Censo 2015 afirma que a evasão nos cursos de graduação EaD ocorre em primeiro lugar por falta de tempo; em segundo, por questões financeiras; em terceiro, pela falta de adaptação à modalidade $\mathrm{EaD}$; e, em seguida, por escolha equivocada. Segundo a ABED (2016, p. 48), "as taxas de evasão dos cursos regulamentados totalmente a distância certamente foram as mais altas. Por outro lado, essa modalidade também foi considerada a mais acessível ao retorno do aluno".

De acordo com a ABED (2016), no ano de 2016, o curso de Pedagogia liderou o número de matrículas em cursos na modalidade $\mathrm{EaD}$ e, no ano de 2018, os cursos de licenciatura receberam o maior número de matrículas (ABED, 2018) Essa será nossa discussão na próxima seção com foco na oferta desse curso em IES do setor privado.

\section{Um olhar para o curso de Pedagogia EaD}


Consideramos que estudar o percurso da implantação das graduações a distância, a partir dos dispositivos legais, disponíveis no Portal MEC, é uma tentativa de conhecer o histórico desta modalidade de ensino, embora não baste apenas um olhar para os documentos de regulação. Há que refletir sobre os dados disponíveis.

Os trabalhos desenvolvidos por Gatti (2009) sobre a formação inicial e o perfil de professores assinalavam, já em 2009, a relação da formação na modalidade a distância. Para Gatti (2009, p. 106), “o esperado é que essa modalidade contribua para diminuir a segmentação do ensino superior no país, aumentando o acesso de estudantes residentes em regiões com menores oportunidades educacionais em relação a esse nível de educação". Esta era a proposta inicial da EaD: chegar até alunos geograficamente distantes dos grandes centros e de Instituições de Ensino Superior. Dessa forma, um primeiro olhar para tais cursos revela uma busca pela criação de oportunidade de formação.

Observando a distribuição regional dos cursos, sua expansão ocorreu em parte na direção desejada dentro de uma perspectiva inclusiva, uma vez que eles teriam contribuído para facilitar o acesso à educação superior no Nordeste. Entretanto, nas regiões Norte e Centro-Oeste, em que as oportunidades educacionais também não são muito abundantes, os cursos de EaD mostraram um crescimento muito pequeno entre 2002 e 2005. (GATTI, 2009, p. 106)

Inicialmente tímida, a oferta de cursos de Pedagogia EaD deu lugar à possibilidade de expansão das Instituições de Ensino Superior privadas, tornando-se um produto altamente vendável.

As pesquisas desenvolvidas por Gatti (2009, p. 110) destacam que "na esfera privada, a concorrência desencadeada pelo custo mais baixo das matrículas de EAD não pode ser suportada por muitos cursos presenciais, cuja manutenção é mais cara". A autora comenta ainda que muitos dos cursos oferecidos na modalidade a distância se realizavam sem uma articulação entre o projeto político-pedagógico de formação docente e as questões que envolviam o âmbito nacional e local.

Para entender essa informação apontada por Gatti (2009), realizamos um levantamento dos valores das mensalidades dos cursos de Pedagogia EaD, praticados por instituições de ensino superior de alcance nacional. Identificamos que a média das mensalidades destes cursos é de R\$244,05; e a IES que apresentou a mensalidade com valor mais baixo foi de R\$ 
$159,20^{4}$. Alguns descontos são praticados pelas IES para os cursos EaD, podendo tornar os preços das mensalidades ainda menores.

Para complementar essa relação entre cursos EaD e os valores praticados, a ABED (2018) apresenta, no relatório do Censo 2017, um gráfico comparativo das faixas de mensalidades entre cursos totalmente a distância, cursos semipresenciais e cursos presenciais.

\footnotetext{
${ }^{4}$ Valores referentes a outubro de 2019.
}

Revista Devir Educação, Lavras, vol.4, n.2, p.411-430 jul./dez., 2020. 
GRÁFICO 2: Faixa de valores de mensalidades

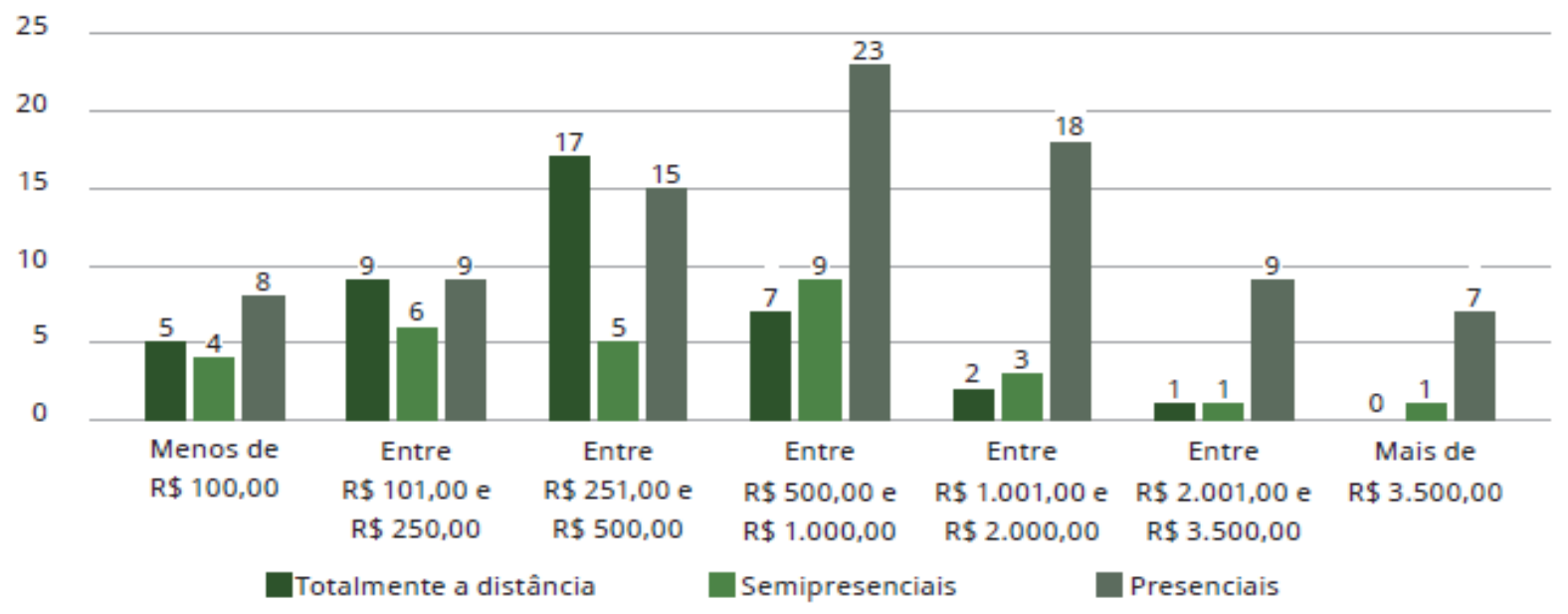

Fonte: (ABED, 2018, p.52)

É possível perceber um intervalo significativo nos valores médios dos cursos de Pedagogia, conforme a modalidade de ensino. A nossa experiência ${ }^{5}$, como professoras em instituições que ofertam cursos nas modalidades presencial e a distância, tem nos mostrado que, muitas vezes, o aluno que se matricula no curso de Pedagogia (tanto na modalidade presencial como a distância) inicia a procura por estágio remunerado logo nos primeiros meses de matriculado, como forma de custear as mensalidades do curso. O valor incompatível entre o que se ganha como estagiário e o da mensalidade de um curso presencial é uma queixa comum dos alunos que procuram a IES, e o discurso dos alunos geralmente afirma que farão a transferência para um curso $\mathrm{EaD}$, pois os valores das mensalidades são mais baixos e possíveis de serem pagos com o dinheiro que recebem no estágio remunerado.

Além da diferença entre os valores de mensalidades, também se questiona o que é qualidade na educação a distância. Para Pequeno (2018), os pilares de uma EaD de qualidade baseiam-se em material didático, avaliação, tutoria e metodologia aplicada, procurando destacar as chamadas Metodologias Ativas ${ }^{6}$ como forma de conseguir uma maior participação dos alunos.

A qualidade na $\mathrm{EaD}$ caminha por espaços que vão além da tecnologia, entre eles a importância das pessoas neste processo de aprender e de ensinar. Reiteremos: qualidade na EaD não é só tecnologia, uma vez que muitos são os recursos tecnológicos disponíveis na

\footnotetext{
${ }^{5}$ Uma das autoras do presente texto atua em educação a distância em rede privada, há 10 anos.

${ }^{6}$ Metodologias Ativas - estratégias que estimulam o engajamento de alunos e o desenvolvimento de capacidade crítica e reflexiva (Mill, 2018).
} 
atualidade para que as aulas sejam pensadas e apresentadas em um curso. O diferencial dos processos, e que tem sido cada vez mais observado, é a gestão das pessoas envolvidas nos cursos EaD. Uma gestão que vai desde o professor conteudista ${ }^{7}$ até o papel do tutor, passando ainda por outros agentes do processo de implantação EaD, como designers instrucionais, designers gráficos, programadores, entre outros.

Gestores de cursos EaD têm voltado a atenção, cada vez mais, para o papel do tutor, tanto o tutor $\mathrm{EaD}$ quanto o tutor presencial, como o grande transformador do processo de educação a distância e as formas de atuação deste tutor. É esse profissional que, nesta modalidade de educação, está mais próximo do aluno e é capaz de estimular o aprendizado. Para Mill (2018), o tutor é o principal agente da EaD, exercendo o papel de mediador e motivador de ensino-aprendizagem e estreitando a comunicação com o aluno.

Neste processo não podemos deixar de nos referir aos alunos e às diferenças pessoais e até ao interesse deles pelo curso. Para Azevedo (2007), frequentemente o aluno considera o curso EaD como uma alternativa para estudar e conseguir qualificar-se para o mundo de trabalho. Muitas vezes essa adesão dá-se devido às propagandas de cursos $\mathrm{EaD}$, que vendem a proposta de um curso com flexibilidade de horários e autonomia da organização do aluno para acompanhar as aulas, conforme sua disponibilidade de tempo.

Essa mesma flexibilidade pode ser uma armadilha para o aluno que não tem ou não consegue construir uma rotina de estudos ou apresenta alguma dificuldade como usuário de informática. Pode-se imaginar que quem escolhe um curso $\mathrm{EaD}$ possua intimidade como usuário de computadores e da tecnologia, mas essa premissa nem sempre é verdadeira. Muitos relatos de alunos de EaD que não possuíam nenhum contato com o computador antes de iniciar o curso apontam essa questão como uma das dificuldades no curso.

O crescimento da abertura de novos cursos de graduação na modalidade EaD relaciona-se não só a uma estratégia para proporcionar acesso ao ensino superior, mas, nas instituições privadas, é visto como uma oportunidade comercial e de expansão dos negócios educacionais.

Gatti et al (2019) aponta que os cursos na modalidade a distância tornam-se de grande interesse para IES privadas, uma vez que permitem atender um número maior de alunos com

\footnotetext{
${ }^{7}$ Professor Conteudista - responsável pela elaboração do material didático de cada unidade curricular de aprendizagem ou disciplina.
}

Revista Devir Educação, Lavras, vol.4, n.2, p.411-430 jul./dez., 2020. 
um menor número de professores e com infraestrutura menos custosa, o que possibilita que os valores desses cursos sejam mais baixos do que os cursos presenciais.

Esse movimento das universidades privadas para a comercialização de cursos é facilmente constatado nos apelos publicitários divulgados na mídia, como uma tentativa de seduzir o candidato a matricular-se. A flexibilidade do tempo para estudar também aparece em sites de IES, quando apresentam seus cursos $\mathrm{EaD}$, e muitas são as referências de que estes cursos possuem qualidade e que o certificado é igual ao do curso presencial.

$\mathrm{O}$ aumento da oferta de vagas e as ações para o barateamento das mensalidades evidenciam problemas quanto a qualidade dos cursos, como:

redução curricular e de horas de formação; currículo com pouca vocação para formar profissionais docentes; expansão geométrica das licenciaturas no formato à distância em condições pouco qualificadas; formação dos docentes das próprias instituições de ensino superior para o trabalho de formação de professores para a Educação Básica. (GATTI, 2017)

Para Castells (2003, p. 51), esse é o reflexo da cultura empresarial "uma cultura do dinheiro. E de dinheiro em quantidades tão assombrosas (assim reza o mito empresarial) que qualquer esforço vale a pena". E continua: “a atividade empresarial, como dimensão essencial da cultura da Internet, chega com uma nova distorção histórica: cria dinheiro a partir de ideias, e mercadorias a partir de dinheiro, tornando tanto o capital quanto a produção, dependentes do poder da mente" (p.52).

Essa comercialização do acesso à formação pode parecer algo natural, se atentarmos para o preconizado pelo modelo socioeconômico neoliberal, em que o destaque é o capital humano, sendo o indivíduo o único responsável por seu sucesso ou fracasso na vida. Há a polarização de riqueza e pobreza, cabendo ao homem e à mulher a busca por adaptar-se às situações sociais e econômicas, e a educação segue esta lógica adaptativa. As conquistas e os resultados na vida de uma pessoa "são fruto de uma série de decisões e esforços que dependem apenas do indivíduo e não implicam nenhuma compensação em caso de fracasso, exceto as previstas nos contratos de seguro privado facultativo" (DARDOT \& LAVAL, 2016, p. 346).

Ainda sob a ótica neoliberal, o papel da EaD é ampliar o número de vagas de acesso da população ao ensino superior. Neste aspecto, a qualidade da formação, a inserção profissional e a conquista de oportunidades profissionais tornam-se responsabilidade de cada indivíduo; só depende dele a criação de condições para adaptar-se às exigências impostas pela 
sociedade. Para este cenário, Bourdieu (2001), com a ideia de excluídos do interior, contribui para nossa reflexão, pois, após conseguir o acesso à educação, o estudante primeiro passaria por um período de ilusão de que alcançou uma oportunidade de mudar sua vida, para depois começar a perceber que esse acesso a um curso não garante a ele a ascensão profissional nem social.

Com efeito, nem sempre o curso $\mathrm{EaD}$ consegue promover a tão prometida e tão buscada inserção profissional, pois as dificuldades contrapõem-se às imagens e às peças promocionais produzidas pelas IES que ofertam tais cursos. A ampliação do número de vagas e o baixo custo dos cursos EaD, em um primeiro momento, aparecem como a solução do processo educacional, como uma espécie de mágica em que se abrem as portas das IES para que mais pessoas possam se matricular; porém, aumentar o acesso não garante que o oferecido seja suficiente para formar profissionais capazes de crescer e tornar-se conhecedores da área em que estão recebendo a certificação. Assim, oportuniza-se o acesso, cumpre-se uma meta educacional, mas exclui-se, quando não se garante um curso de qualidade e a inserção profissional na área de formação.

Atualmente, os cursos EaD oportunizam o estudo, o acesso à informação, a tecnologia ao alcance do aluno, a formação que atende à legislação. Todavia, para falarmos de qualidade na educação EaD como algo que transcende a tecnologia, ainda há muito o que conquistar na implantação dos cursos, de forma a garantir o engajamento do aluno, o aproveitamento integral do material didático, com um plano de ensino realmente preparado para a EaD e não mera reprodução do projeto para o ensino presencial.

Para Laval (2019), o mundo neoliberal vê a educação como um bem econômico e privado, e atribui ao indivíduo a responsabilidade de capitalizar recursos que terão como rendimentos futuros sua ação na sociedade - uma sociedade de mercado, movida pela competição e pela adaptação. Ademais, afirma o autor, nessa concepção cabe à escola formar profissionais flexíveis, que utilizem a tecnologia, que se autogerenciem e se autodisciplinem, dotando-se de conhecimento ao longo de sua vida, garantindo assim seu potencial de empregabilidade. Para prover esse espaço, surgem as universidades-empresas, como indústrias de produção do saber, que criam oportunidades para rentabilizar o ensino e oferecer conhecimento como bens úteis.

Não obstante, não tomamos a $\mathrm{EaD}$ como vilã no processo educacional, porém discutimos ser ela o efeito de todo processo neoliberal, em que a educação assume o lugar de 
produto. Se conduzida nesta perspectiva, a EaD pode legitimar a exclusão, uma vez que promove oportunidade de formação e, se o sujeito fracassar, a responsabilidade é apenas dele, que continuará a buscar outras formações para preencher lacunas de sua formação inicial.

Com a flexibilização da EaD, ou melhor, com a mudança nas regras para abertura de novos polos educacionais, o que possibilitou o aumento de polos de $\mathrm{EaD}$ no País, previsto pelo Decreto n. ${ }^{\circ} 9.057 / 2017$, tende a aumentar a oferta de cursos e vagas nesta modalidade, tal como se oferece um produto nas prateleiras - procedimento nomeado por alguns pesquisadores de "industrialização da educação". Importa acompanhar esse movimento de expansão, entendendo e considerando a necessidade de pensar cursos que, dentro da modalidade $\mathrm{EaD}$, realmente sejam formadores de pessoas que possam sentir-se preparadas para o exercício da profissão e capazes de uma atuação crítica, reflexiva e ativa na sociedade.

Um outro fato a discutir é que, ainda hoje, é possível encontrar cursos de Pedagogia (presencial e $\mathrm{EaD}$ ) que não se articulam com a comunidade ou com as questões locais ou nacionais. Não é raro encontrar propostas pedagógicas que procuram atender às Diretrizes Curriculares Nacionais (DCN), descrevendo no Projeto Pedagógico do Curso (PPC) possíveis ações a serem realizadas na formação docente, mas que, em uma análise apurada, revelam que, fora do PPC, faltam ações específicas nesta articulação, ações capazes de propiciar ao aluno de $\mathrm{EaD}$ um encontro com a prática educativa.

É importante apoiar estudos que abordem as questões relativas à gestão desse modelo de formação no Brasil, as articulações em rede, a integração de EAD nos Planos de Desenvolvimento Institucional das IES, que tragam evidências empíricas sobre o funcionamento das dimensões específicas dos cursos no interior das instituições e que avaliem os impactos dessa modalidade de ensino quanto a aprendizagens profissionais efetivas. (GATTI, 2009, pp. 113-114)

Lopes e Pereira (2017) consideram que a Educação a Distância é um fenômeno histórico, marcado por todas as contingências sociais; antes de se falar em Educação a Distância, há que se falar em Educação como um processo histórico, social e político, pois, muitas vezes, as concepções de educação a distância aproximam-se daquelas da educação presencial.

Ainda vivenciamos situações em que a modalidade a distância é vista como paliativo do ensino presencial e tem sido uma alternativa em que a presença física de um estudante em uma instituição de ensino tornava-se impossível. Nesse caso, a concepção de Educação a Distância fica reduzida à não presença em sala de aula. (PIMENTEL, 2017, p. 26)

Revista Devir Educação, Lavras, vol.4, n.2, p.411-430 jul./dez., 2020. 
A caracterização de um curso $\mathrm{EaD}$ não se restringe ao aspecto não presencial do aluno em aula. Esse é apenas o elemento disparador da arquitetura e da concepção do ensino ali praticado. Cabe às IES planejar as estratégias e as metodologias que irão compor o PPC e que viabilizem uma formação adequada; em contrapartida, compete ao estudante valorizar sua autonomia e aprimorar o foco na autoaprendizagem, características estas fundamentais para uma participação ativa no curso. Importa, ademais, a ambos os componentes dessa estrutura, considerar que as tecnologias presentes no dia a dia da sociedade contemporânea possibilitam outras formas de interação entre as pessoas, muito diversas das relações estabelecidas num tempo não tão distante. E fazer uso inteligente e efetivo delas no exercício de seu direito de trocar saberes e de seu dever de bem fazê-lo.

\section{Considerações Finais}

A análise dos dados aqui apresentados evidencia que, desde o início da regulamentação e da oferta dos Cursos Superiores $\mathrm{EaD}$, eles se apresentam com forte vínculo com a formação de professores e que, ainda hoje, o curso de Pedagogia é o Curso Superior EaD com maior número de matrículas. Essa expansão, sem controle na qualidade dos cursos ofertados, pode comprometer a formação do professor que atua na educação infantil e nos anos iniciais do ensino fundamental (estudantes de 0 a 11 anos).

Do primeiro dispositivo legal sobre a educação a distância até o presente momento, muitas transformações aconteceram, tanto no cenário social como tecnológico, sendo notórios os avanços da tecnologia e as possibilidades de construir plataformas e aplicativos que possibilitem a comunicação entre as pessoas. Mas, ao pensar em tecnologia, importa ter a clareza de que nem todas as regiões e pessoas do País possuem acesso a uma internet de qualidade e que viabilize uma participação ativa nos cursos de EaD.

Apesar de a tecnologia não ser o único diferencial entre um curso presencial e um curso a distância, sem um acesso adequado à tecnologia, o aluno de um curso EaD fica limitado à leitura de textos, visto que, muitas vezes, o acesso a vídeos e as interações síncronas $^{8}$, em tempo real, acabam ficando inviabilizados. Por essa razão, é cada vez mais

\footnotetext{
${ }^{8}$ Interações Síncronas - são aquelas comunicações que acontecem em tempo real, por exemplo, com a utilização de chats e videoconferências.
}

Revista Devir Educação, Lavras, vol.4, n.2, p.411-430 jul./dez., 2020. 
presente entre aqueles que planejam cursos $\mathrm{EaD}$ a procura por plataformas, ambientes virtuais e outros recursos de comunicação virtual que possam ser acessados por conexões via smartphones, visto que esta tecnologia está nas mãos de um grande contingente da população brasileira, superando hoje o número de computadores em residências.

Também ocorreram mudanças no perfil das IES que oferecem cursos EaD e dos alunos que buscam estes cursos. Se, no início da oferta da graduação na modalidade $\mathrm{EaD}$, o foco era atender a formação de professores com cursos oferecidos em instituições públicas de ensino superior para pessoas que residiam longe dos grandes centros, hoje, são diversos os cursos de graduação oferecidos por instituições públicas e privadas, em diferentes áreas do conhecimento, e o perfil do aluno deixou de ser aquele que está longe dos grandes centros, pois deslocou-se para o aluno que busca o curso com o menor custo financeiro das mensalidades.

Ainda há muito o que pesquisar sobre cursos na modalidade a distância, porém, mais do que discutir suas estratégias e ferramentas de aprendizagem, é preciso pensar o curso como detentor de peculiaridades bem distintas da modalidade presencial e analisar e planejar ações com foco na busca e na manutenção da qualidade da formação, independentemente da modalidade de educação utilizada.

\section{Referências}

ABED. Anuário Brasileiro Estatístico de Educação Aberta e a Distância - 2005. São Paulo: Instituto Monitor, 2005.

ABED. Censo EaD.BR: Relatório Analítico da Aprendizagem a Distância no Brasil 2015. Curitiba: Ibpex, 2016.

ABED. Censo EaD.BR: Relatório Analítico da Aprendizagem a Distância no Brasil 2016. Curitiba: Ibpex, 2017.

ABED. Censo EaD.BR: Relatório Analítico da Aprendizagem a Distância no Brasil 2017. Curitiba: InterSaberes, 2018.

AZEVEDO, D. R. O Aluno Virtual: perfil e motivação. Florianópolis: Universidade do Sul de Santa Catarina, 2007.

BOURDIEU, Pierre (org). A miséria do mundo. 4. ed. Petrópolis: Vozes, 2001. 
BRASIL. Portaria n. ${ }^{0}$ 11, de 20 de junho de 2017. Disponível em: http://abmes.org.br/arquivos/legislacoes/Port-Normativa-011-2017-06-20.pdf Acesso em: 17 set. 2019.

BRASIL. Lei n. ${ }^{\circ}$ 9.394, de 20 de dezembro de 1996. Disponível em: <http://portal.mec.gov.br/sesu/arquivos/pdf/lei9394.pdf> Acesso em: 20 mai. 2017.

BRASIL. Decreto n. ${ }^{\circ}$ 2.494, de 10 de fevereiro de 1998. Disponível em: <http://portal.mec.gov.br/seed/arquivos/pdf/tvescola/leis/D2494.pdf> Acesso em: 21 mai. 2017.

BRASIL. Decreto n. ${ }^{\circ} \mathbf{2 . 5 6 1}$, de 27 de abril de 1998. Disponível em: <http://portal.mec.gov.br/seed/arquivos/pdf/tvescola/leis/D2561.pdf> Acesso em: 17 set. 2019.

BRASIL. Portaria MEC n. ${ }^{0}$ 335, de 6 de fevereiro de 2002. Disponível em: <http://portal.mec.gov.br/sesu/arquivos/pdf/lei9394.pdf> Acesso em: 20 mai. 2017.

BRASIL. Portaria n. ${ }^{\circ}$ 4.059, de 10 de dezembro de 2004. Disponível em: <http://portal.mec.gov.br/sesu/arquivos/pdf/nova/acs_portaria4059.pdf> Acesso em: 20 mai. 2017.

BRASIL. Decreto n. ${ }^{\circ}$ 5.622, de 19 de dezembro de 2005. Disponível em: <http://portal.mec.gov.br/sesu/arquivos/pdf/portarias/dec5.622.pdf> Acesso em: 20 mai. 2017.

BRASIL. Documento de Recomendações "Ações Estratégicas em Educação Superior a Distância em Âmbito Nacional”. BRASILIA: GTEADES/MEC/SESu, 2005. Disponível em: <http://portal.mec.gov.br/sesu/arquivos/pdf/acoes-estrategicas-ead.pdf> Acesso em: 20 mai. 2017.

BRASIL. Portaria n. ${ }^{0}$ 873, de 7 de abril de 2006. Disponível em: <http://portal.mec.gov.br/sesu/arquivos/pdf/portarias/portaria873.pdf> Acesso em: 20 mai. 2017.

BRASIL. Decreto $\mathbf{n}^{\mathbf{0}} \mathbf{5 . 8 0 0}$, de 06 de junho de 2006. Disponível em: <http://www.planalto.gov.br/ccivil_03/_Ato2004-2006/2006/Decreto/D5800.htm> Acesso em: 17 set. 2019.

BRASIL. Referenciais de Qualidade para Educação Superior a Distância. Brasília: MEC, 2007. Disponível em: <http://portal.mec.gov.br/seed/arquivos/pdf/legislacao/refead1.pdf> Acesso em: 20 mai. 2017.

BRASIL. Parecer n. ${ }^{\circ}$ 195, de 13 de setembro de 2007. Disponível em: <http://portal.mec.gov.br/cne/arquivos/pdf/2007/pces195_07.pdf> Acesso em: 17 set. 2019.

BRASIL. Parecer n. ${ }^{\circ}$ 197, de 13 de setembro de 2007. Disponível em: <http://portal.mec.gov.br/cne/arquivos/pdf/2007/pces197_07.pdf> Acesso em: 17 set. 2019. 
BRASIL. Portaria n. ${ }^{\circ}$, de 10 de janeiro de 2007. Disponível em: <http://portal.mec.gov.br/seed/arquivos/pdf/legislacao/portaria2.pdf> Acesso em: 17 set. 2019.

BRASIL. Relatório de Gestão 2008. Secretaria de Educação a Distância. Brasília: MEC, $2008 . \quad$ Disponível em: <http://portal.mec.gov.br/index.php?option=com_docman\&view=download\&alias=27072relatoriogestaopara-spo14-04-20091canexo\&category_slug=janeiro-2010pdf\&Itemid=30192> Acesso em: 20 mai. 2017.

BRASIL. Parecer n. ${ }^{\circ}$ 564, de 10 de dezembro de 2015. Disponível em: <http://www.abed.org.br/arquivos/parecer_cne_ces_564_15.pdf> Acesso em: 17 set. 2019.

BRASIL. Resolução n. ${ }^{0}$, de 11 de março de 2016. Disponível em: <http://portal.mec.gov.br/index.php?option=com_docman\&view=download\&alias=35541 res-cne-ces-001-14032016-pdf\&category_slug=marco-2016-pdf\&Itemid=30192> Acesso em: 20 mai. 2017.

BRASIL. Decreto n. ${ }^{\circ}$ 9.057/2017, de 25 de maio de 2017. Disponível em: $<$ http://portal.mec.gov.br/index.php?option=com_docman\&view=download\&alias=65251 decreto9057-pdf\&category_slug=maio-2017-pdf\&Itemid=30192> Acesso em: 06 ago. 2018.

CASTELLS, Manuel. A galáxia da Internet: reflexões sobre a internet, os negócios e a sociedade. 1 ed. Rio de Janeiro: Jorge Zahar ,2003.

DARDOT, Pierre; LAVAL, Christian. A nova razão do mundo: ensaio sobre a sociedade neoliberal. 1 ed. São Paulo: Boitempo, 2016.

GATTI, Bernardete Angelina; BARRETO, Elba Siqueira de Sá; ANDRÉ, Marli Eliza Dalmazo Afonso de; ALMEIDA, Patrícia Cristina Albieri de. Professores do Brasil: novos cenários de formação. Brasília: UNESCO, 2019.

GATTI, Bernardete Angelina. Formação de professores, complexidade e trabalho docente. Revista Diálogo Educacional, v. 17, n. 53, p. 721-737, ago. 2017. Disponível em: https://periodicos.pucpr.br/index.php/dialogoeducacional/article/view/8429 Acesso em: 31 jul. 2020.

GATTI, Bernardete Angelina (org). Professores do Brasil: impasses e desafios. 1 ed. Brasília: UNESCO, 2009.

LAVAL, Christian. A Escola não é uma empresa: O neoliberalismo em ataque ao ensino público. 1. ed. Londrina: Editora Planta, 2004.

LOPES, Luis Fernando; PEREIRA, Maria de Fatima Rodrigues. O que e o quem da EaD. In: PEREIRA, Maria de Fatima Rodrigues; MORAES, Raquel de Almeida; TERUYA, Teresa Kasuco (org). Educação a Distância (EaD): Reflexões críticas e práticas. Uberlândia: Navegando Publicações, 2017, p. 9-23. 
MILL, D. Dicionário Crítico de Educação e Tecnologias e de Educação a Distância. 1 ed. São Paulo: Papirus, 2018.

PEQUENO, Mauro. Qual é o papel da ABED na discussão da qualidade da EaD no Brasil? In: ABED. Censo EaD.BR: Relatório Analítico da Aprendizagem a Distância no Brasil 2017. Curitiba: InterSaberes, 2018. p. 13-15.

PIMENTEL, Nara. A modalidade a distância no Brasil: aspectos conceituais, políticos e tecnológicos. In: PEREIRA, Maria de Fatima Rodrigues; MORAES, Raquel de Almeida; TERUYA, Teresa Kasuco (org). Educação a Distância (EaD): Reflexões críticas e práticas. Uberlândia: Navegando Publicações, 2017, p.25-39.

Recebido em 06/06/2020

Aprovado em 05/08/2020 